\title{
Nutritional Composition, Antioxidant Activity and Common Phytochemicals of Selected BARI Mango Varieties and Commercial Cultivar Langra
}

\author{
Mohammad Mainuddin Molla, Ashfak Ahmed Sabuz, Md. Golam Ferdous Chowdhury, Md. Hafizul \\ Haque Khan, Mahfujul Alam, Md. Miaruddin, Anjumanara Khatun and Md. Sekender Ali
}

\begin{abstract}
The present study sought to explore the nutritional composition, bioactive phytochemicals and antioxidant activity of BARI mango-4, BARI mango-6 and Langra cultivar. The total phenolic (TPH), vitamin $C$, total carotene, B-carotene content and antioxidant activity of the mangos were determined by 1,1- diphenyl-2picryl hydrazyl (DPPH) scavenging and reducing power assays (RPA). Phenolic compounds were assessed using high-performance liquid chromatography coupled with a photodiode array detector and auto sampler. Results revealed that moisture, TSS, pH, total acidity, reducing, total sugar and energy of the BARI mango-4 and BARI mango-6 were 76.54 and $75.24 \%$, $17.10^{\circ} \mathrm{B}$ and $21.20^{\circ} \mathrm{B}, 4.90$ and $5.01,0.49$ and $0.50 \%, 3.90$ and $4.54 \%, 11.20$ and $13.46 \%$ and 4028.06 and $3950.27 \mathrm{cal} / \mathrm{g}$ respectively whereas the Langra cultivar remained $76.33 \%$, $17.63^{\circ} \mathrm{B}, 4.25,0.63 \%, 2.79 \%, 9.79 \% \%$ and $3871.28 \mathrm{cal} / \mathrm{g}$ respectively. Phytochemicals especially TPH, ascorbic acid, total flavonoid (TF), total carotenoid (TC), B-carotene and total anthocyanin content (TAC) of the BARI mango-4 and BARI mango-6 were 20.53 and $20.67 \mathrm{mg} \mathrm{GAE} / \mathrm{g}, 39.98$ and 26.26 $\mathrm{mg} / 100 \mathrm{~g}, 3.14 \mathrm{mg}$ and $2.87 \mathrm{QE} / \mathrm{g}, 76.38$ and $81.33 \mathrm{mg} / 100 \mathrm{~g}$, 28.17 and $65.84 \mu \mathrm{g} / 100 \mathrm{~g}$ and 1.67 and $11.69 \mathrm{mg} / 100$ respectively whereas the Langra contained $19.90 \mathrm{mg} \mathrm{GAE} / \mathrm{g}$, $25.53 \mathrm{mg} / 100 \mathrm{~g}, 1.38 \mathrm{mg} \mathrm{QE} / \mathrm{g}, 4.21 \mathrm{mg} / 100 \mathrm{~g}, 31.00 \mu \mathrm{g} / 100 \mathrm{~g}$ and18.22 $\mathrm{mg} / 100 \mathrm{~g}$ respectively. In case of antioxidant activities total antioxidant capacity, DPPH radical scavenging activity, reducing power capacity (RPC), metal chelating capacity (MCC), Nitric oxide (NO) free radical scavenging activity and IC $_{50}$ of the BARI mango-4 and BARI mango-6 were 229.00 and $309.00 \mu \mathrm{g}$ of ascorbic acid/mg of extract, 96.84 and $94.73 \%$, 12.20 and $9.71 \mu \mathrm{g} / \mathrm{mL}, 157.36$ and $132.89 \%, 61.74$ and 72.65 $\mu \mathrm{g} / \mathrm{mL}$ and 0.59 and $0.71 \mu \mathrm{g} / \mathrm{mL}$ respectively whereas the Langra cultivar contained $194.25 \mu \mathrm{g}$ of ascorbic acid/mg of extract, $87.94 \%, 2.54 \mu \mathrm{g} / \mathrm{mL}, 177.80 \%, 53.74 \mu \mathrm{g} / \mathrm{mL}$ and 25.11 $\mu \mathrm{g} / \mathrm{mL}$ respectively. The results indicate that BARI mango-4 and BARI mango-6 exhibited rich source of TPH, TC, Bcarotene, ascorbic acid, TA, TAC and NO free radical scavenging activity whereas the Langra is the rich source of MCC and anthocyanin content. Phenolic acids were leading agent in BARI mango-4 and BARI mango-6. Moreover, BARI
\end{abstract}

Published on November 21, 2020.

Mohammad Mainuddin Molla, Postharvest Technology Division, Bangladesh Agricultural Research Institute (BARI), Bangladesh.

(e-mail: mainuddinmolla@ ${ }^{@}$ yahoo.com)

Ashfak Ahmed Sabuz, Postharvest Technology Division, Bangladesh Agricultural Research Institute (BARI), Bangladesh.

Md. Golam Ferdous Chowdhury, Postharvest Technology Division, Bangladesh Agricultural Research Institute (BARI), Bangladesh.

Md. Hafizul Haque Khan, Postharvest Technology Division, Bangladesh Agricultural Research Institute (BARI), Bangladesh.

Mahfujul Alam, Postharvest Technology Division, Bangladesh Agricultural Research Institute (BARI), Bangladesh.

Md. Miaruddin, Research Wing, BARI, Bangladesh.

Anjumanara Khatun, Institute of Food Science and Technology, BCSIR, Bangladesh.

Md. Sekender Ali, Department of Agricultural Extension and Information System, Sher-e-Bangla Agricultural University, Bangladesh. mango-4 and BARI mango-6 extract had a great potential to fight free radical chain reactions and for usage in therapeutic applications.

Index Terms - Mangoes; nutrients; bioactive compounds; antioxidants.

\section{INTRODUCTION}

Bangladesh is blessed with the greatest diversity of fruits and in 2017 placed the $6^{\text {th }}$ position in world ranking for tropical fresh fruit production [1]. A significant quantity of tropical fruits become underexploited, which are generally recognized as indigenous or minor fruits. Major fruits like mango, litchi, guava, banana, jackfruit etc. are commercially cultivated in Bangladesh. Among the major fruits, mango (Mangifera indica L.) is called the king of the fruits and may be due to its deliciousness and very popular among all ages of the people. There are over 500 classes of mango varieties; some of them have evolved and have been distributed throughout the world. The main mango producing countries of the world are India, Pakistan, Mexico, Brazil, Haiti, Philippines, and Bangladesh [2]. Mangoes grow widely throughout the Bangladesh and are raised mostly as homestead plantations. The leading mango producing districts are Chapai Nawabgonj, Rajshahi and Satkhira areas with a large number of superior varieties namely Fazlee, Langra, Gopalbhog, Himsagar, Khirsapat, Kohitoor, Laksmanbhog, Chausa, Amrapali, Mallika, Mohanbhog, Misribhog etc. [2]. The soil and climatic conditions of Bangladesh especially northern and eastern regions are suitable for commercial mango cultivation [3]. But the BARI varieties is grown almost all over the country and are renowned for their emblematic taste, high TSS content $\left(15^{\circ} \mathrm{B}-26^{\circ} \mathrm{B}\right)$, fruit weight $(207.67-433.67 \mathrm{~g})$, yield (13-22 t/ha), taste and highly adaptation to different regions in Bangladesh. These mango varieties have a great demand throughout the Bangladesh and have commercial importance in the agro-food processing industries.

Bangladesh Agricultural Research Institute (BARI) up to now developed 11 mango varieties that are being tried introduced and disseminated to all over the country. Moisture content, titrable acidity, $\mathrm{pH}$, TSS, total sugar, reducing sugar, total protein, total fat, crude fiber, ash, total carbohydrate, total energy value, vitamin-C content and heavy metals have been analyzed by the Ara et al. [2] only for the commercial cultivars. The detail studies for its nutritional composition, minerals, antioxidant activities and phytochemical compounds are still now meager for both commercial and BARI mango varieties. Among the various 
phytochemicals, polyphenolic compounds comprising phenolic acids, flavonoids, benzoic acids derivatives and other compounds are linked with natural protective agents, astringency, antibiotics, positive health effects or antimicrobial properties [4]. In recent years, interests for antioxidant-rich fruits and their products is growing in both domestic and international markets because of increasing appreciation of their role in the protection of human health.

Nowadays, antioxidants are also considered as important as vitamins for promotion of health and prevention of various diseases linked to reactive oxygen species (ROS) and scarcity of vitamin-C. ROS have been linked to over 100 disorders [5]. Excess generation of ROS causes oxidative stress that damage DNA, lipids and proteins of cells leading to pathogenesis of various diseases including CVDs. Vitamin-C may contribute to promote the health beneficial effect for the COVID-19 patients. Minerals are essential for good health and nutrition, advancing physical and intellectual development. Low dietary intake of mineral rich foods as well as low absorption and lower bioavailability of those minerals are the leading cause of the micronutrient deficiencies. Since nutrition database is of great importance in addressing nutritional health benefits and it is essential for planning of food, nutrition, and health related policy tools for the country and pharmaceutical industries. From these points of view, the present study has undertaken for analyzing and documentation of phytochemicals, nutritional composition, minerals, and antioxidant properties and for comparing those with commercial variety to promote nutritional health of the people.

\section{MATERIALS AND Methods}

The materials were BARI mango-4, BARI mango- 6 and Langra cultivar. Analytical grade chemicals and reagents used in this study were procured from Millipore Sigma (Merck KGaA).

\section{A. Sampling}

The sample used for the analysis was collected from the Fruit Research Field of Horticulture Research Center (HRC), BARI, Gazipur-1701, Bangladesh. The fruits were harvested and collected when attained physiological maturity. Three fruits trees for each variety was scientifically tagged in the orchard and randomly fifty fruits were harvested from each tree for each variety. There were three replications (one tree comprises one replication) and each replication contained fifty fruits. Thus 600 fruits $(50 \times 1 \times 3 \times 4)$ were harvested from three replications of the two varieties (BARI mango-4 and BARI mangio-6).

\section{B. Determination of Physical Characters}

Physical characters such as weights of fruit, peel and seed weight were measured by digital electrical balance. The edible and non-edible portion of the fruit was measured using the gravimetric method.

\section{Determination of Physicochemical Parameter}

The physicochemical properties of the fruit in terms of moisture, total sugar, reducing sugar, total soluble solids
(TSS), $\mathrm{pH}$ and titratable acidity were determined as per the method mentioned by AOAC [6]. Starch and total sugar content were determined based on the procedure of Ranganna [7].

\section{Preparation of Fruit Extract}

The fruits were washed with potable water and peeled using peeler. After peeling, the fruits were sliced and freezedried to make powder using a laboratory grinder. The powdered samples were either used for the extraction or packed in HDPE pouch [8] and stored at $-18{ }^{\circ} \mathrm{C}$ until used for analysis. Fruit powder of known quantity was extracted in a thermostatic water bath (Vision Scientific Co. Ltd.) at $60{ }^{\circ} \mathrm{C}$ for $60 \mathrm{~min}$. using methanol $(80 \%$, v/v) maintaining the fruit to solvent ratio of 1:20 (w/v). The fruit extract was filtered under vacuum, centrifuged at $4000 \times \mathrm{g}$ for $10 \mathrm{~min}$ and supernatant were collected and kept at $-18{ }^{\circ} \mathrm{C}$ until used for analysis.

\section{E. Determination of Phytochemicals}

\section{a) Total phenolic content}

Twenty milligrams ( $0.02 \mathrm{~g})$ of powder were dissolved in $1 \mathrm{~mL}$ of methanol to prepare a stock-solution for experiments. A volume of $0.5 \mathrm{~mL}$ of the each extract $(100 \mu \mathrm{g} / \mathrm{mL})$ was mixed with $2 \mathrm{~mL}$ of the Folin-Ciocalteu reagent (diluted 1:10 with de-ionized water) and were neutralized with $4 \mathrm{~mL}$ of sodium carbonate solution $(7.5 \%$, $\mathrm{w} / \mathrm{v})$. The reaction mixture was incubated at room temperature for $30 \mathrm{~min}$. with intermittent shaking for color development. The absorbance of the colored solution was measured at $765 \mathrm{~nm}$ using double beam UV-VIS spectrophotometer. The total phenolic content was determined from the linear equation of a standard curve prepared with gallic acid. The content of total phenolic compounds expressed as $\mathrm{mg} / \mathrm{g}$ gallic acid equivalent (GAE) of dry extract. Determination of total phenolic content in the extracts was determined according to the Folin-Ciocalteu method [9] with gallic acid (GAE) as the standard and expressed (mg) as gallic acid equivalents (GAE)/g of extract [10].

\section{b) Determination of total flavonoid content}

The total flavonoid content (TFC) of the fruit powder was determined by aluminium chloride method [11] with slight modifications. Sample solution was prepared by mixing fruit powder in methanol at a concentration of $1 \mathrm{mg} / \mathrm{ml} .0 .5 \mathrm{ml}$ of sample solution was then mixed with $1.5 \mathrm{ml}$ of methanol. To this mixture $0.1 \mathrm{ml}$ of $10 \%$ aluminium chloride and $0.1 \mathrm{ml}$ of $1 \mathrm{M}$ potassium acetate was added. The final volume was made to $5 \mathrm{ml}$ by adding $2.8 \mathrm{ml}$ distilled water and left the reaction for 30 minutes at room temperature. The absorbance of the reaction mixture solution was measured at $415 \mathrm{~nm}$ using UV-vis spectrophotometer. The TFC was calculated based on $\mathrm{R}^{2}$ value of the calibration curve and expressed as milligram quercetin equivalent per gram of extract (mg QE/g extract).

\section{c) Determination of ascorbic acid content}

Ascorbic acid was determined according to the method described by Ranganna [7]. 


\section{d) Determination of total anthocyanin}

The method was adapted from Burgos et al. [12]: $0.2 \mathrm{~g}$ of freeze-dried samples was mixed with $10 \mathrm{~mL}$ of methanol/ $1.0 \mathrm{M} \mathrm{HCl}(75: 25, \mathrm{v} / \mathrm{v})$ and sonicated for $10 \mathrm{~min}$ at room temperature. The mixture was centrifuged at $5000 \mathrm{rpm}$ for $10 \mathrm{~min}$. and the pellet was re-extracted. The combined supernatants were filtered and the volume made up to $25 \mathrm{~mL}$ with the extraction solution. Absorbance of the extract was read at 545, 535 and $515 \mathrm{~nm}$ and the concentration of TA was calculated using the molar extinction coefficient and molecular weight of malvidin-3-p-coumaroyl-glucoside for blue-violet pigments $\left(545 \mathrm{~nm}, 3.02 \times 10^{4} \mathrm{~L} / \mathrm{mol} / \mathrm{cm}\right.$, $718.5 \mathrm{~g} / \mathrm{mol})$, pelargonidin-3-glucoside for red pigments (515 nm, 2.73 $\times 10^{4} \mathrm{~L} / \mathrm{mol} / \mathrm{cm}, 486.5 \mathrm{~g} / \mathrm{mol}$ ), and cyanidin-3glucoside for purple pigments $\left(535 \mathrm{~nm}, 3.43 \times 10^{4} \mathrm{~L} / \mathrm{mol} / \mathrm{cm}\right.$, $449.2 \mathrm{~g} / \mathrm{mol}$ ). Results were expressed in $\mathrm{mg} / 100 \mathrm{~g} \mathrm{DW}$.

\section{e) Determination of total carotenoid content}

Determination of total carotenoid content performed by Thaipong et al. [13] method. The extracted fruit powder was dissolved in $\mathrm{n}$-hexane pro analysis. 3 -carotene solution in various concentrations was used as standard of carotenoid compound and to be standard curve. Absorbance was measured at $470 \mathrm{~nm}$. Linear regression equation of standard curve was used for calculating total carotenoid content. Results were expressed as beta-carotene equivalent per $100 \mathrm{~g}$ of powder $(\mathrm{mg} / 100 \mathrm{~g})$.

\section{f) Determination of $\beta$-carotene content}

$\beta$-carotene content was determined using the procedure of Holden et al. [14] and the value was expressed as $\mu \mathrm{g} / 100 \mathrm{~g}$ of fruit powder.

\section{F. Determination of Antioxidant Activity}

\section{a) Total antioxidant activity}

The total antioxidant activity was assessed by the phosphomolybdenum system rendering to the technique described by Prieto et al. [15]. Briefly, $0.3 \mathrm{~g}$ of fruit powder was taken in a glass tube and $3 \mathrm{~mL}$ of reagent solution (0.6 M sulphuric acid, $28 \mathrm{mM}$ sodium phosphate and $4 \mathrm{mM}$ ammonium molybdate) was added. The mixture was heated at $95{ }^{\circ} \mathrm{C}$ in a water bath for $90 \mathrm{~min}$. Then the mixture was cooled at room temperature and the absorbance was read at $695 \mathrm{~nm}$. The result was stated as microgram ascorbic acid (AA) per gram $(\mu \mathrm{g} / \mathrm{mL})$ of the sample.

\section{b) Reducing power assay}

The reducing power of the fruit powder was assessed using the approach of Guo et al. [16]. The fruit powder $(0.2 \mathrm{~g})$ was mixed with $0.5 \mathrm{~mL}$ phosphate buffer $(0.2 \mathrm{M}, \mathrm{pH}$ 6.6) and $0.5 \mathrm{~mL}$ potassium ferricyanide $(1 \% \mathrm{w} / \mathrm{v})$ and mixed properly. The mixture was then incubated at $50^{\circ} \mathrm{C}$ for $30 \mathrm{~min}, 0.5 \mathrm{~mL}$ of trichloro acetic acid $(10 \%$, w/v) was added, subjected to centrifugation for $10 \mathrm{~min}$. The upper portion of the solution $(0.5 \mathrm{~mL})$ was taken, mixed with $0.1 \mathrm{~mL}$ of $0.1 \%(\mathrm{w} / \mathrm{v}) \mathrm{FeCl}_{3}$ and $0.5 \mathrm{~mL}$ distilled water. The absorbance was noticed at $700 \mathrm{~nm}$ and ascorbic acid was used as the standard for the preparation of the calibration curve. c) $D P P H$ radical scavenging activity (DPPH-RSA) and $I C_{50}$

The 2, 2-diphenyl-1-picrylhydrazyl (DPPH) radical quenching property was evaluated by measuring the inhibition rate following the procedure described by BrandWilliams et al. [17] with some alteration. Exactly $0.1 \mathrm{mg}$ of the fruit powder was put into a falcon tube and $1.4 \mathrm{~mL}$ methanolic solution of DPPH was added. The mixture was left in rest for $30 \mathrm{~min}$ in dark and the absorbance at $517 \mathrm{~nm}$ was measured against blank $(0.1 \mathrm{~mL}$ methanol in $1.4 \mathrm{~mL}$ DPPH solution). The result was stated in terms of percent radical scavenging activity.

$$
\text { DPPH radical scavenging activity }(\%)=\frac{A_{O}-A_{s}}{A_{O}} \times 100
$$

where, $A_{o}$ is absorbance of blank and $A_{s}$ is absorbance of sample extract. Then, the inhibition curves were prepared and $\mathrm{IC}_{50}$ values were calculated [17]. BHT was the positive control.

\section{d) Metals chelating capacity}

The metal chelating capacity (MCC) was determined based on Bahadori et al. [18] with little modification. Briefly, $2 \mathrm{mg}$ fruit powder was taken in a glass tube to which $0.05 \mathrm{~mL}$ ferrous chloride $(2 \mathrm{mM}), 3.7 \mathrm{~mL}$ distilled water, and $0.2 \mathrm{~mL}$ ferrozine $(5 \mathrm{mM})$ were added. After 20 min of incubation at atmospheric condition, the absorbance was read at $562 \mathrm{~nm}$ against blank. The following formula was applied to calculate the metal-chelating capacity.

$$
\begin{aligned}
& \text { Metal chelating capacity (\%) } \\
& =\frac{\text { Absorbance }(\text { control })-\text { Absorbance (sample) }}{\text { Absorbance }(\text { control })} \times 100
\end{aligned}
$$

\section{e) Nitric oxide radical scavenging activity}

Nitric oxide radical quenching activity was determined according to the procedure of Bogucka-Kocka et al. [19] with some modification. Shortly, $0.5 \mathrm{mg}$ fruit powder was taken in a glass tube to which $2 \mathrm{~mL}$ sodium nitroprusside $(10 \mathrm{mM})$ was mixed. This was followed by incubation at the atmospheric condition for $60 \mathrm{~min}$. Thereafter, $0.5 \mathrm{~mL}$ incubated mixture was transferred into another centrifuge tube and Griess reagent $(0.5 \mathrm{~mL})$ was added and kept in rest for $30 \mathrm{~min}$. The absorbance of the solution was read at $540 \mathrm{~nm}$ against blank. The following formula was employed to calculate the result and expressed as percent inhibition.

$$
\begin{aligned}
& \text { Inhibition (\%) } \\
& =\frac{\text { Absorbance }(\text { control })-\text { Absorbance }(\text { sample })}{\text { Absorbance }(\text { control })} \times 100
\end{aligned}
$$

\section{G. Assessment of Phenolic Acids by HPLC}

Phenolic compounds were assessed according to Pandey and Negi [20] with some adjustment using highperformance liquid chromatography (Shimadzu SPDM10A) coupled with a photodiode array detector and auto sampler at 280 and $320 \mathrm{~nm}$. The separation was achieved by C18 column $(250 \mathrm{~mm} \times 4.6 \mathrm{~mm})$ with $5 \mu \mathrm{m}$ particle size at 
room temperature. The mobile phase was $1 \%$ acetic acid (A) and $80 \%$ acetonitrile in $\mathrm{A}(\mathrm{B})$. The following gradient was followed: $0.01-35 \mathrm{~min}, 0 \%$ of $\mathrm{B} ; 35-40 \mathrm{~min}, 50 \%$ of $\mathrm{B}$; 40 $45 \mathrm{~min}, 100 \%$ of $\mathrm{B}$; and $45-60 \mathrm{~min}, 0 \%$ of $\mathrm{B}$. The flow rate was $1 \mathrm{~mL} / \mathrm{min}$, and the injection capacity was $20 \mu \mathrm{L}$. A total of $60 \mathrm{~min}$ was taken for chromatographic analysis. All solvents used for HPLC were degassed using vacuum filter. Six phenolic standards (P-courmaric acid, gallic acid, vanillic acid, caffeic acid, ferulic acid, and lutein) were used for identification of respective phenolics, and quantification was accomplished using standard curve prepared by injecting the mixture of all the standards $(0.1-0.7 \mathrm{mg} / \mathrm{mL})$.

\section{H. Statistical Analysis}

Data obtained for each analysis were expressed in duplicate as means (3 replications) \pm standard deviation. Data was analyzed by One-way ANOVA with post-hoc using Turkey Multiple Comparisons Test. The significance was defined at the $95 \%$ confidence level. Statistical analysis and data processing were performed using software SPSS 17.0 (IBM INC., New York).

\section{RESUlts AND DisCUSSION}

\section{A. Physico-Chemical Properties}

The physicochemical properties of the BARI mango-4, BARI mango- 6 and commercial cultivar Langra are shown in Table 1. Results revealed that TSS of the BARI mango-4, BARI mango- 6 and Langra were statistically differed and found maximum in BARI mango- $6\left(21.20^{\circ} \mathrm{B}\right)$.The TSS obtained by Ara et al. [2] for the ten commercial mango cultivars ranged from 12.87 to $21.05{ }^{\circ}$ Brix which indicates that BARI mango varieties contain higher amount of TSS. As a reason it is said that BARI varieties were obtained from our own orchard and it was physiologically matured than Ara et al. [2]. They [2] collected samples from the market and sometimes market samples found physiologically immature and treated by ripening agents. $\mathrm{pH}$ of the BARI mango-4, BARI mango-6 and Langra found 4.93, 5.01and 4.25 whereas the acidity calculated as $0.49 \%, 0.50 \%$ and $0.63 \%$ respectively. The results obtained by Ara et al. [2] for the $\mathrm{pH}$ and acidity of the ten commercial cultivars ranged from 4.35 to 4.70 and 0.30 to $0.75 \%$. It is noted that BARI mango-4 and BARI mango-6 had higher $\mathrm{pH}$ and lower acidity than the results obtained by Ara et al. [2] and Langra cultivar. However, TSS, $\mathrm{pH}$ and acidity varied for all the varieties and these variations might be due to different cultivars, fruit maturity and ripening with the conversion of pectic substances. Moisture content of the BARI mango-4, BARI mango-6 and Langra found $76.54 \%, 75.27 \%$ and $76.33 \%$ respectively $\mathrm{FW}$ while it was reported from 78.078 to $79.078 \%$ FW by Maldonado-Celis [21] for different Colombia, Mexico and United States mango cultivars. Total sugar and reducing sugar content of the BARI mango varieties and Langra cultivar varied significantly $(\mathrm{p}<0.05)$ and ranged from 9.79-13.46 \% and 2.79-4.54\% respectively. Ara et al. [2] reported reducing sugar content for ten commercial cultivars and ranged from 4.27 to 5.48 $\%$. Here, it is noteworthy that BARI mango variety had higher total sugar and reducing sugar content than the commercial cultivar Langra. Literature suggest that the variation of total sugar content depends on the nature of the fruit maturity, time of harvest, oxidation of important constituents, soil conditions and differences in composition [22]. Energy is essential for rest, activity, growth, and maintenance of sound health. Its content is of concern to health-conscious consumers [23]. The highest energy (4028.28 Kcal/g1) found in BARI mango-4 whereas the lowest was recorded as $3950.28 \mathrm{Kcal} / \mathrm{g}$ and $3871.28 \mathrm{Kcal} / \mathrm{g}$ in BARI mango-6 and Langra cultivar (Table 1).

TABLE 1: PHYSICO-CHEMICAL PROPERTIES OF BARI MANGO-4, BARI

\begin{tabular}{|c|c|c|c|c|}
\hline \multicolumn{5}{|c|}{ MANGO-6 AND LANGRA } \\
\hline Parameter & $\begin{array}{c}\text { BARI } \\
\text { mango-4 }\end{array}$ & $\begin{array}{c}\text { BARI } \\
\text { mango-6 }\end{array}$ & Langra & LSD \\
\hline $\begin{array}{c}\text { Moisture } \\
\text { content (\%) }\end{array}$ & $76.54 \pm 0.04$ & $75.27 \pm 0.03$ & $76.33 \pm 1.70$ & $* *$ \\
\hline $\begin{array}{c}\text { Total } \\
\text { soluble } \\
\text { solid }\left({ }^{\circ} \mathrm{B}\right)\end{array}$ & $17.10 \pm 0.03$ & $21.20 \pm 0.04$ & $17.63 \pm 0.02$ & $* *$ \\
\hline $\mathrm{pH}$ & $4.90 \pm 0.03$ & $5.01 \pm 0.01$ & $4.25 \pm 0.04$ & $*$ \\
\hline Acidity (\%) & $0.49 \pm 0.02$ & $0.50 \pm 0.03$ & $0.63 \pm 0.02$ & $* *$ \\
\hline $\begin{array}{c}\text { Total sugar } \\
(\%)\end{array}$ & $11.20 \pm 0.02$ & $13.46 \pm 0.04$ & $9.79 \pm 0.02$ & $* *$ \\
\hline $\begin{array}{l}\text { Reducing } \\
\text { sugar }(\%)\end{array}$ & $3.90 \pm 0.02$ & $4.54 \pm 0.04$ & $2.79 \pm 0.05$ & $* *$ \\
\hline $\begin{array}{l}\text { Energy } \\
\text { (Kcal/g) }\end{array}$ & $4028.06 \pm 0.04$ & $3950.28 \pm 0.02$ & $3871.28 \pm 0.06$ & $* *$ \\
\hline
\end{tabular}

All values are means of triplicate determinations $\pm \mathrm{SD}$. * indicates significant result at $\mathrm{p}<0.05$; ** indicates significant result at $\mathrm{p}<0.01$.

\section{B. Phytochemicals Properties}

Phytochemicals or bioactive compounds e.g. phenolic acids, carotenoids, and vitamins, naturally exist in foodstuffs including fruits, vegetables, herbs, and spices [24]. These components supposed to have the ability to lower the prevalence of different degenerative diseases such as cancer, heart attack, and cardiovascular disease etc. by terminating the free radical's activity [25]. Literature supports that stages of fruit maturity, cultural practice and processing technique are directly influenced these phytochemicals [24].

The results recorded for the phytochemical analyses such as total phenolic, flavonoids, carotenoids, $\beta$-carotene, ascorbic acid, and anthocyanin are presented in Table 2. Total phenolic content of the BARI mango-4 and BARI mango- 6 found 20.53 and $20.67 \mathrm{mg} \mathrm{GAE} / \mathrm{g}$ DM whereas the Lnagra possessed $19.90 \mathrm{mg}$ GAE/g DM. The lower phenolic content obtained by the Langra cultivar than the BARI mango-6 might be due to the effect of regional soil characteristics, fruit maturity, time of harvest, fruit and orchard nature [22]. Our results are supported with the findings of Burgos et al. [12], who reported that pineapple and passion fruit had a polyphenol content of $21.7 \mathrm{mg}$ GAE/100g and $20.2 \mathrm{mg} \mathrm{GAE} / 100 \mathrm{~g}$ DM, respectively.

Flavonoids are regarded as a low molecular weight substance exists in foodstuffs, which boosts the antioxidants activity [11]. Its content depends on the amount of polyphenols and geographical locations. The value of total flavonoids existing in the examined BARI mango-4 and BARI mango-6 found 3.14, 2.87 and $1.38 \mathrm{mg}$ QE/g while the highest was recorded in BARI mango-4 (3.14 mg QE/g).Total flavonoid content of Thailand ten mango cultivars were reported by Maldonado-Celis et al. [21] and ranged from 0.035 to $13.09 \mathrm{mg}$ QE/g DM. Since flavonoids 
possessed a fair amount of flavonoids like other exotic fruits, its consumption would help to contribute to add antioxidants to our daily diet.

It is evidenced from different studies that carotenoid has a crucial part in human nutrition and health, which can lessen the risks of cancer and heart diseases because of the activity of pro-vitamin A [24]. It can be seen that total carotenoids and total $\beta$-carotene content of the BARI mango-4 and BARI mango- 6 found as 76.38 and $81.33 \mathrm{mg} / 100 \mathrm{~g}$ and 28.17 and $65.84 \mu \mathrm{g} / 100 \mathrm{~g}$, respectively while it was recorded in Langra cultivar $4.21 \mathrm{mg} / 100 \mathrm{~g}$ and $31.00 \mu \mathrm{g} / 100$ $\mathrm{g}$ respectively (Table 2). Results show that BARI mango-6 donated higher amount of total carotenoids and total $\beta$ carotene content than BARI mango-4 and Langra cultivar. The total carotenoids contained in our examined sample is comparable to the reported by Haque et al. [26] for the twelve mango varieties while it ranged from 108.00 to $444.66 \mu \mathrm{g} / 100 \mathrm{~g}$.

Studies evidenced that ascorbic acid is considered as the most powerful antioxidants in foodstuffs whose regular intake lowers the cancer risks in the human body [27]. However, ascorbic acid is also considered as the most unstable compounds existing in foodstuffs and its content depends on various factors such as heat, $\mathrm{pH}$, metal content, oxygen content etc. [28]. Therefore, the indication of nutrient loss in foodstuffs is evaluated through the containment of its ascorbic acid. Interestingly, the ascorbic acid content of the BARI mango- 4 and BARI mango- 6 found 39.98 and $26.26 \mathrm{mg} / 100 \mathrm{~g} \mathrm{FW}$ while the Langra was recorded as $25.53 \mathrm{mg} / 100 \mathrm{~g} \mathrm{FW}$. Total ascorbic acid content of five commercial mango varieties (Tommy Atkins, Keitt, and Kent) was reported by Manthey and Perkins-Veazie [29] as $22 \mathrm{mg} / 100 \mathrm{~g} \mathrm{FW}$. In addition, total ascorbic acid content of three commercial mango varieties ranged from 15.80 to $16.4 \mathrm{mg} / 100 \mathrm{~g}$ those reported by Dars et al. [30]. FAO [31] reported that jackfruit which is recognized as the national fruit of Bangladesh contained $11.08 \mathrm{mg} / 100 \mathrm{~g}$ ascorbic acid content. Results obtained from our study indicates that BARI mango is the rich source of ascorbic acid than Langra cultivar and Jackfruit and the results obtained by Manthey and Perkins-Veazie [29] and Dars et al. [30]. According to Jukes [32], the RDA of vitamin C, i.e. ascorbic acid to prevent scurvy for adults is about $10 \mathrm{mg}$, which indicates that the current study found a higher amount of ascorbic acid that can prevent scurvy adequately with daily consumption of $100 \mathrm{~g}$ of mango fruit. One of the important bioactive compounds existent in foodstuffs is the anthocyanin. Previous research supported that this compound showed potent antioxidant capacity. The anthocyanin content of the BARI mango-4, BARI mango-6 and Langra cultivar were highly significant. The highest anthocyanin content was recorded as $18.22 \mathrm{mg} / 100 \mathrm{~g}$ in Langra cultivar than the BARI mango varieties. This value is well supported with the previous findings of Rufino et al. [33] who reported that strawberries had anthocyanin content as $21 \mathrm{mg} / 100 \mathrm{~g}$.
TABLE 2: PHYTOCHEMICAL PROPERTIES OF BARI MANGO-4, BARI MANGO6 AND LANGRA

\begin{tabular}{ccccc}
\hline Parameter & $\begin{array}{c}\text { BARI } \\
\text { mango-4 }\end{array}$ & $\begin{array}{c}\text { BARI } \\
\text { mango-6 }\end{array}$ & Langra & LSD \\
\hline Anthocyanin & $1.67 \pm 0.02$ & $11.69 \pm 0.01$ & $18.22 \pm 0.04$ & $* *$ \\
Total phenolic & $20.53 \pm 0.03$ & $20.67 \pm 0.07$ & $19.90 \pm 7.20$ & $*$ \\
Ascorbic acid & $39.98 \pm 0.01$ & $26.26 \pm 0.05$ & $25.53 \pm 0.02$ & $* *$ \\
$\begin{array}{c}\text { B-carotene } \\
\text { Total } \\
\text { flavonoid } \\
\text { Total }\end{array}$ & $28.17 \pm 0.03$ & $65.84 \pm 0.04$ & $31.00 \pm 0.90$ & $* *$ \\
carotenoid & $76.38 \pm 0.01$ & $81.33 \pm 0.01$ & $4.21 \pm 0.17$ & $* *$ \\
\hline
\end{tabular}

All values are means of triplicate determinations $\pm \mathrm{SD}$. * indicates significant result at $\mathrm{p}<0.05 ; * *$ indicates significant result at $\mathrm{p}<0.01$.

\section{Evaluation of Antioxidant Activity}

Present research has reported that major fruits are an ample source of different bioactive compounds and phytochemicals, which contribute to their antioxidant properties. Antioxidants terminate the free radical reactions and purify the harmful actions of it. Foodstuffs with high antioxidants properties play a crucial role in the inhibition of reactive oxygen species (ROS) tempted diseases [34].

In this investigation, the antioxidant activity of BARI mango- 4 and BARI mango- 6 was assessed by an assortment of different tests and the findings of these analyses are shown in Table 3. Statistically a highly significant difference was observed among the BARI mango varieties and Langra cultivar those exhibited a potent antioxidant activity. Total antioxidant capacity of the BARI mango-4 and BARI mango- 6 was 229.00 and $309.00 \mu \mathrm{g}$ of ascorbic $\mathrm{acid} / \mathrm{mg}$ of extract while the Langra cultivar was $194.25 \mu \mathrm{g}$ of ascorbic acid/mg of extract. Results indicate that BARI mango is the rich source of antioxidant capacity than the commercial cultivar Langra. The highest antioxidant capacity obtained in BARI mango varieties might be the result of the abundances of phenolic constituents of the fruit [35].

The DPPH of the BARI mango-4, BARI mango- 6 and Langra cultivar found $96.84 \%, 94.73 \%$ and $87.94 \%$ respectively while the almost similar results (2.91 to 92.00 $\%$ ) have been reported by Anaya-Esparza and MontalvoGonzalez [36]. Results revealed that BARI mango varieties exhibited strong capacity to scavenge free radicals' activities. The $\mathrm{IC}_{50}$ is a widely accepted method to assess the antioxidant activity of foodstuffs and its value is expected to be lower for higher free radical quenching ability [37]. Our study exposed that BARI mango-4 and BARI mango-6 extract had potential antioxidant capacity due to its lower value of $\operatorname{IC}_{50}(0.59$ and $0.71 \mu \mathrm{g} / \mathrm{mg})$, which might be due to the presence of significant amounts of phenolics and flavonoids. This finding is also corroborated with the forgoing research of Sathyanarayanan et al. [37]. The reducing power assay (RPA) of the BARI mango-4 and BARI mango- 6 found 12.20 and $9.71 \mu \mathrm{g} / \mathrm{mL}$ while the lower value $2.54 \mu \mathrm{g} / \mathrm{mL}$ recorded in Langra cultivar. Lower metal chelating capacity (MCC) was recorded as $157.36 \%$ and $132.89 \%$ in BARI mango-4 and BARI mango- 6 while the highest MCC $177.80 \%$ was recorded in Langra cultivar. It indicates that the capability of the BARI mango varieties and Langra cultivar to reduce different metallic ions to make a stable chemical bond to fight free radicals. Modern studies reported that redox properties of phenolic species let them perform as reducing agents by donating hydrogen and 
quenching the singlet oxygen that shows antioxidant activity and chelates metal ions [38]. Previous reports evidenced that fruits with high phenolic can react with free radicals to form a stable product that ceases the radical-chain-reaction [37]. Reactive nitrogen species (RNS) are notorious to produce nitric oxide radicals, which could convert into toxic oxidants and nitrating agents. This RNS has been linked with many health complications like cardiovascular diseases, cancer, asthma, Alzheimer, diabetes etc. [39]. Our study reported a good nitric oxide radical foraging activity in BARI mango-4 and BARI mango-6 recorded as 61.74 and $72.65 \mu \mathrm{g} / \mathrm{mL}$ whereas the lowest was in Langra cultivar $(53.74 \%)$. The highest nitric oxide free radical scavenging activity might have attributed owing to the presence of different polyphenolic substances in BARI mango varieties.

TABLE 3: ANTIOXIDANT PROPERTIES OF BARI MANGO-4, BARI MANGO-6

\begin{tabular}{|c|c|c|c|c|}
\hline \multicolumn{5}{|c|}{ AND LANGRA } \\
\hline Parameter & $\begin{array}{c}\text { BARI } \\
\text { mango-4 }\end{array}$ & $\begin{array}{c}\text { BARI } \\
\text { mango-6 }\end{array}$ & Langra & LSD \\
\hline $\begin{array}{l}\text { DPPH radical } \\
\text { scavenging } \\
\text { activity }(\%)\end{array}$ & $96.84 \pm 0.02$ & $94.73 \pm 0.02$ & $87.94 \pm 1.19$ & $* *$ \\
\hline $\begin{array}{l}\text { Total antioxidant } \\
\text { capacity ( } \mu \mathrm{g} \text { of } \\
\text { ascorbic acid/mg } \\
\text { of extract) }\end{array}$ & $229.00 \pm 1.00$ & $309.00 \pm 1.00$ & $194.25 \pm 1.00$ & $* *$ \\
\hline $\begin{array}{c}\text { Metal chelating } \\
\text { capacity }(\%)\end{array}$ & $157.36 \pm 0.06$ & $132.89 \pm 0.09$ & $177.80 \pm 0.40$ & $* *$ \\
\hline $\begin{array}{l}\text { Reducing power } \\
\text { assay }(\mu \mathrm{g} / \mathrm{mL})\end{array}$ & $12.20 \pm 0.02$ & $9.71 \pm 0.01$ & $2.54 \pm 0.02$ & $* *$ \\
\hline $\begin{array}{l}\text { Nitric oxide free } \\
\text { radical } \\
\text { scavenging } \\
\text { activity }(\mu \mathrm{g} / \mathrm{mL})\end{array}$ & $61.74 \pm 0.03$ & $72.65 \pm 0.05$ & $53.74 \pm 0.0$ & $* *$ \\
\hline $\mathrm{IC}_{50}(\mu \mathrm{g} / \mathrm{mL})$ & $0.59 \pm 0.01$ & $0.71 \pm 0.00$ & $25.11 \pm 2.70$ & $* *$ \\
\hline
\end{tabular}

All values are means of triplicate determinations \pm SD. ** indicates significant result at $\mathrm{p}<0.01$.

\section{Phenolic Compounds}

The chromatograms and values obtained for phenolic acids are displayed in Fig. 1, 2 and 3 and Table 4. Five major phenolic acids were analyzed by High-Performance Liquid Chromatography and matched with the respective standards. Results depict that BARI mango varieties are plentiful of phenolic acids. Among the identified phenolic acids, gallic, vanilic, caffeic and ferulic acid of the BARI mango-4 and BARI mango- 6 found 17.52 and $19.11 \mathrm{mg} /$ $100 \mathrm{~g}, 4.36$ and $5.71 \mathrm{mg} / 100 \mathrm{~g}, 2.16$ and $19.4 \mathrm{mg} / 100 \mathrm{~g}$ and 10.27 and $8.08 \mathrm{mg} / 100 \mathrm{~g}$ respectively whereas the Langra cultivar recorded as $0.95 \mathrm{mg} / 100 \mathrm{~g}, 0.16 \mathrm{mg} / 100 \mathrm{~g}$, $0.48 \mathrm{mg} / 100 \mathrm{~g}, \quad 0.15 \mathrm{mg} / 100 \mathrm{~g}$ and $0.31 \mathrm{mg} / 100 \mathrm{~g}$ respectively. Gallic, vanillic, caffeic and ferulic acid of the nine mango varieties cultivated in China ranged from 0.93 to $2.98 \mathrm{mg} / 100 \mathrm{~g}, 0.57$ to $1.63 \mathrm{mg} / 100 \mathrm{~g}, 0.25$ to $0.10 \mathrm{mg} /$ $100 \mathrm{~g}$ and 0 to $33.75 \mathrm{mg} / 100 \mathrm{~g} \mathrm{FW}$ [21]. Results show that BARI mango varieties contain higher amount of gallic, vanillic and caffeic acids followed by Chinese nine mango varieties. However, BARI mango-4 and BARI mango-6 was rich source of phenolic acids that act as defense against different hazardous chemical reactions and diseases, and their involvement in antioxidants depends on their structure [40].
TABLE 4: PHENOLIC COMPOUNDS OF BARI MANGO-4, BARI MANGO-6 AND LANGRA

\begin{tabular}{ccccc}
\hline Parameter & $\begin{array}{c}\text { BARI } \\
\text { mango-4 }\end{array}$ & $\begin{array}{c}\text { BARI } \\
\text { mango-6 }\end{array}$ & Langra & LSD \\
\hline $\begin{array}{c}\text { Gallic acid } \\
(\mathrm{mg} / 100 \mathrm{~g})\end{array}$ & $17.52 \pm 0.02$ & $19.11 \pm 0.01$ & $0.95 \pm 0.02$ & $* *$ \\
$\begin{array}{c}\text { Vanilic acid } \\
(\mathrm{mg} / 100 \mathrm{~g})\end{array}$ & $4.36 \pm 0.02$ & $5.71 \pm 0.01$ & $0.16 \pm 0.01$ & $* *$ \\
$\begin{array}{c}\text { P-courmaric } \\
\text { acid (mg/100g) } \\
\text { Caffeic acid } \\
(\mathrm{mg} / 100 \mathrm{~g})\end{array}$ & $0.11 \pm 0.02$ & $0.23 \pm 0.01$ & $0.48 \pm 0.02$ & $* *$ \\
$\begin{array}{c}\text { Ferulic acid } \\
(\mathrm{mg} / 100 \mathrm{~g})\end{array}$ & $10.27 \pm 0.01$ & $8.08 \pm 0.02$ & $0.31 \pm 0.02$ & $* *$ \\
\hline
\end{tabular}

All values are means of triplicate determinations $\pm \mathrm{SD}$. ** indicates significant result at $\mathrm{p}<0.01$.

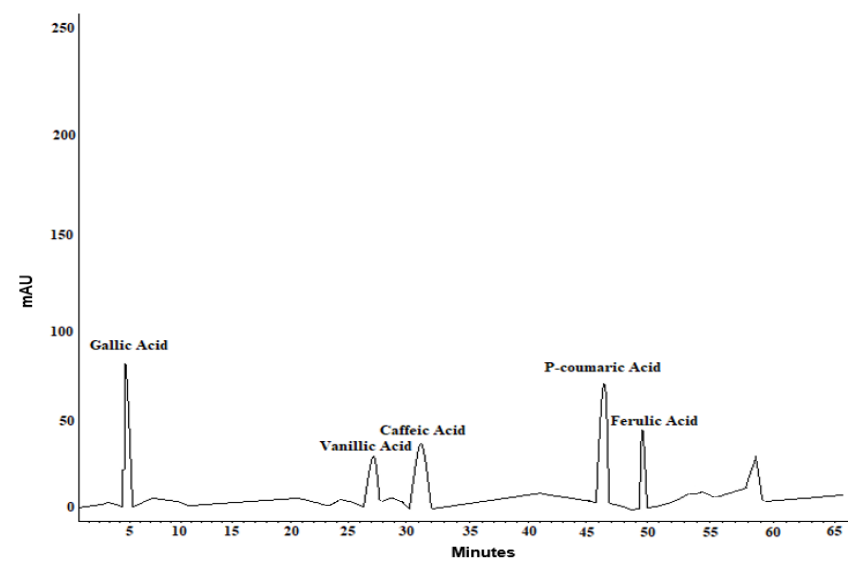

Fig. 1. Chromatogram of Phenolic acid of methanolic extracts of BARI mango-4.

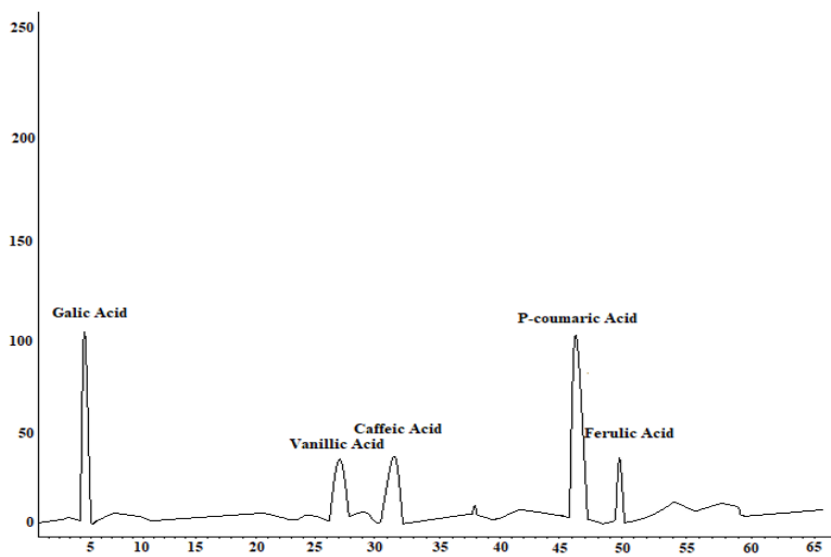

Fig. 2. Chromatogram of Phenolic acid of methanolic extracts of BARI

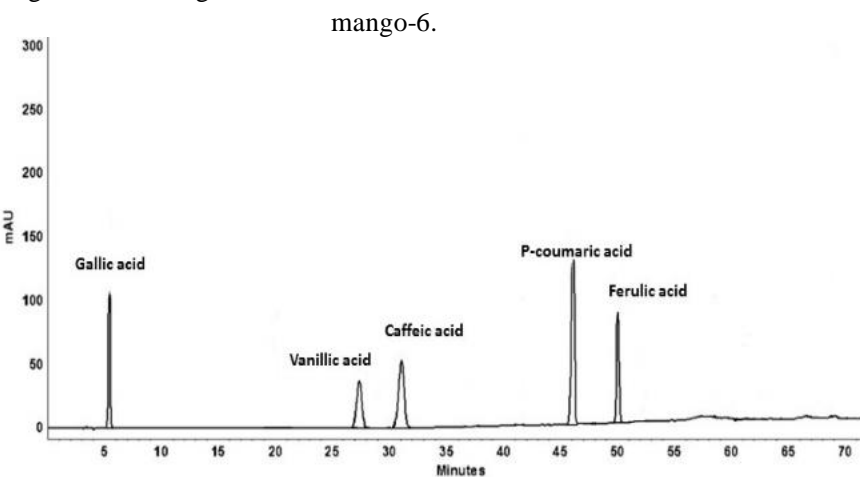

Fig. 3. Chromatogram of Phenolic acid of methanolic Langra fruits extracts. 


\section{CONCLUSION}

This study first time exposed the details information regarding the nutritional, bioactive compounds and antioxidant activities profiling of the selected BARI mango4 and BARI mango-6. From the present findings, it can be concluded that BARI mango-4 and BARI mango- 6 is the rich source of TPH, ascorbic acid, TC, $ß$-carotene, TAC and NO whereas the Langra is the rich source of anthocyanin and MCCw22. Phenolic acids are the leading agents in BARI mango varieties than the cultivar Langra. The findings showed a promising standpoint for possible exploitation of this fruit to be applied as the raw material for food and pharmaceutical usages. Further research studies are recommended using different modern extraction methods for isolation of health beneficial constituents for pharmaceutical usages.

\section{ACKNOWLEDGMENT}

We thankfully acknowledged the Ministry of Science and Technology, Bangladesh Secretariat, Dhaka, Bangladesh for their financial assistance to conduct the study under the project "Comparison of Nutrient Composition, Antioxidant Activity and Common Phytochemicals of the Selected BARI Mango Varieties" (MOST grant Serial, BS-172).

\section{REFERENCES}

[1] FAO STAT(2019) Statistics Division, Food and Agriculture Organization of the United Nations. Viale delle Terme di Caracalla 00153 Rome, Italy.

[2] Ara R, Motalab M, Uddin MN, Fakhruddin ANM, Saha BK (2014) Nutritional evaluation of different mango varieties available in Bangladesh. International Food Research Journal 21: 2169-2174.

[3] BBS (2006) Year Book of Agricultural Statistics, Statistics Division, Ministry of Planning, Government of the People's Republic of Bangladesh.

[4] Osorio-Esquivel O, Alicia-Ortiz-Moreno A, Álvarez VB, DorantesÁlvarez L, Giusti MM (2011) Phenolics, betacyanins and antioxidant activity in Opuntia joconostle fruits. Food Research International: 2160-2168.

[5] Halliwell B, Gutteridge JMC (2000) Free radicals in biology and medicine. Oxford Science Publications, Oxford. pp. 617-624.

[6] AOAC (2005) Official Methods of Analysis, Association of Official Analytical Chemists. Arlington, VA, United States of America.

[7] Ranganna S (1995) Handbook of Analysis and Quality Control for Fruit and Vegetable Products, Second ed., McGraw Hill publishing Co. Ltd., New Delhi. pp.1169.

[8] Shishir MRI, Taip FS, Saifullah M, Aziz NA, Talib RA (2017) Effect of packaging materials and storage temperature on the retention of physicochemical properties of vacuum packed pink guava powder. Food Packaging Shelf life 12: 83-90.

[9] Ough CS, Amerine MA (1988) Phenolic compounds, In: Methods for analysis of musts and wines, J Wiley and Sons, Inc., New York, USA.

[10] Aoshima H, Hirata S, Ayabe S (2007) Antioxidative and AntiHydrogen Peroxide Activities of Various Herbal Teas. Food Chemistry 103: 617-622.

[11] Chang CC, Yang MH, Wen HM, Chern JC (2002) Estimation of total flavonoid content in propolis by two complementary colorimetric methods. Journal of Food and Drug Analysis 10:178-182.

[12] Burgos G, Amoros W, Muñoa L, Sosa P, Cayhualla E, Sanchez C, Díaz C, Bonierbale M (2013) Total phenolic, total anthocyanin and phenolic acid concentrations and antioxidant activity of purple-fleshed potatoes as affected by boiling. Journal of Food Composition Analysis 30: 6-12.

[13] Thaipong K, Boonprakob U, Crosby K, Cisneros-Zevallos L, Hawkins Byrne D, Comparison of ABTS, DPPH, FRAP, and ORAC assays for estimating antioxidant activity from guava fruit extracts. Journal of Food Compositiona Analysis 19:669-675.
[14] Holden JM, Eldridge AL, Beecher GR, Marilyn Buzzard I, Bhagwa S, Davis S, Schakel CS (1999) Carotenoid Content of U.S. Foods: An Update of the Database. Journal of Food Composition and Analysis 12:169-196.

[15] Prieto P, Pineda M, Aguilar M (1999) Spectrophotometric quantitation of antioxidant capacity through the formation of a phosphomolybdenum complex: Specific application to the determination of vitamin E. Analytical Biochemistry 269: 337.

[16] Guo H, Saravanakumar K, Wang M (2018) Total phenoli Stachys affinis. Biocatalysis and Agricultural Biotechnology 15:235-239.

[17] Brand-Williams W, Cuvelier ME, Berset C (1995) Use of a free radical method to evaluate antioxidant activity. LWT Food Science and Technology 28:25-30.

[18] Bahadori MB, Zengin G, Bahadori S, Dinparast L, Movahhedin N (2018) Phenolic composition and functional properties of wild mint (Mentha longifolia var. calliantha (Stapf) Briq.). International Journal of Food Properties 21:198-208.

[19] Bogucka-Kocka A, Zidorn C, Kasprzycka M, Szymczak G, Szewczyk K (2018) Phenolic acid content, antioxidant and cytotoxic activities of four Kalanchoë species. Saudi Journal of Biological Science 25:622630.

[20] Pandey A, Negi PS (2018) Phytochemical composition, in vitro antioxidant activity and antibacterial mechanisms of Neolamarckia cadamba fruits extracts. Natural Product Research 32:1189-1192.

[21] Maldonado-Celis ME, Yahia EM, Bedoya R, Landázuri P, Loango N, Aguillón J, Restrepo B, Guerrero Ospina JC (2019) Chemical Composition of Mango (Mangifera indica L.) Fruit: Nutritional and Phytochemical Compounds. Frontiers and Plant Sciences 10: 1073.

[22] Ahmed M., Akter MS, Lee JC, Eun JB (2010) Encapsulation by spray drying of bioactive components, physicochemical and morphological properties from purple sweet potato. LWT Food Science andTechnology 43:1307-1312.

[23] Liji A, Dibaka S (2015) Quality evaluation of a raw jackfruit based ready to cook (RTC) mix. International Journal of Applied Home Science 2(11\&12):316-323.

[24] Tiburski JH, Rosenthal A, Deliza R, de Oliveira Godoy RL, Pacheco S (2011) Nutritional properties of yellow mombin (Spondias mombin L.) pulp. Food Research International 44: 2326-2331.

[25] Wang S, Melnyk JP, Tsao R, Marcone MF (2011) How natural dietary antioxidants in fruits, vegetables and legumes promote vascular health. Food Research International 44:14-22.

[26] Haque S, Begum P, Khatun M, Islam SN (2015) Total carotenoid content in some mango (Mangifera indica) varieties of Bangladesh International Journal of Pharmaceutical Sciences and Research 6:4875-4878.

[27] Almeida MMB, de Sousa PHM, Arriaga ÂMC, do Prado GM, Magalhães de C, Maia GA, de Lemos TLG (2011) Bioactive compounds and antioxidant activity of fresh exotic fruits from northeastern Brazil. Food Research International 44: 2155-2159.

[28] Mondal SC, Kamal, MM, Mumin MIA, Hosain MM, Ali MR (2017) Effect of sucrose on the physicochemical properties, organoleptic qualities and shelf-life stability of aonla (Emblica Officinalis) candy. IOSR Journal of Environmental Science Toxicology and Food Technology 11:85-94.

[29] Manthey JA, Perkins-Veazie P (2009) Influences of harvest date and location on the levels of beta-carotene, ascorbic acid, total phenols, in vitro antioxidant capacity, and phenolic profiles of five commercial varieties of mango (Mangifera indica L.). Journal of Agricultural Food Chemistry 57: 10825-10830. doi: 10.1021/jf902606h.

[30] Dars AG, Hu K, Abbas A, Chen Y, Khaskheli A A, Liu Q, Li X, Homaida MA, Lakho ABJ, Bijun Xie B, Sun Z (2018) Comparative analysis of antioxidant activities of different varieties of mangos with some selected fruits. African Journal of Agricultural Research 13 1633-1640.

[31] FAO (2010) The State of Food Insecurity in the World: Addressing food insecurity in protracted crises, Food and Agriculture Organization of the United Nations Publishing Policy and Support Branch, Office of Knowledge Exchange, Research and Extension, FAO, Viale delle Terme di Caracalla, 00153 Rome, Italy.

[32] Jukes TH (1974) Are recommended daily allowances for vitamin C adequate? Proceedings of the National Academy of Sciences of the United States of America. 71:1949-1951.

[33] Rufino M do SM, Alves RE, de Brito ES, Pérez-Jiménez J, SauraCalixto F, Mancini-Filho J(2010) Bioactive compounds and antioxidant capacities of 18 non-traditional tropical fruits from Brazil. Food Chemistry 121: 996-1002.

[34] Dutta S, Ray S ( 2018) Comparative assessment of total phenolic content and in vitro antioxidant activities of bark and leaf methanolic extracts of Manilkara hexandra (Roxb.) Dubard. Journal of King Saud University-Science. https://doi.org/10.1016/j.jksus.2018.09.015. 
[35] Garzón GA, Narváez CE, Riedl KM, Schwartz SJ (2010) Chemical composition, anthocyanins, non-anthocyanin phenolics and antioxidant activity of wild bilberry (Vaccinium meridionale Swartz) from Colombia. Food Chemistry 122: 980-986.

[36] Anaya-Esparza LM, Montalvo-Gonzalez E (2018) Nutritional quality of Mangifere Species. Laboratorio de Microbiología de Alimentos, Departamento de Ciencias Pecuarias y Agrícolas, Universidad de Guadalajara, Centro Universitario de los Altos, Tepatitlán de Morelos, Jalisco, Mexico.

[37] Sathyanarayanan S, Chandran R, Thankarajan S, Abrahamse H, Thangaraj P (2018) Phytochemical composition, antioxidant and antibacterial activity of Syzygium calophyllifolium Walp fruit. Journal of Food Science and Technology 55:341-350.

[38] Elfalleh W, Kirkan B, Sarikurkcu C (2018) Antioxidant potential and phenolic composition of extracts from Stachys tmolea: An endemic plant from Turkey. Industrial Crops and Products 127: 212-216.

[39] Pistón M, Machado I, Branco CS, Cesio V, Heinzen H, Ribeiro D, Freitas M (2014) Infusion, decoction and hydroalcoholic extracts of leaves from artichoke (Cynara cardunculus L. subsp. cardunculus) are effective scavengers of physiologically relevant ROS and RNS. Food Research International 64:150-156.

[40] Vicente AR, Manganaris GA, Sozzi GO, Crisosto CH (2014) Nutritional Quality of Fruits and Vegetables. Postharvest Handling, third eds., Elsevier Inc., pp. 69-122.

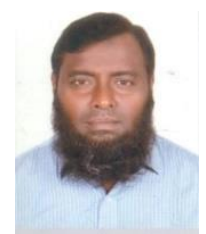

Mohammad Mainuddin Molla was born in Narsingdi, Dhaka, Bangladesh on the 10th day of December, 1979.

He obtained his B.Sc Degree in Agricultural Engineering major in Food Technology and M.S. in Food Technology in 2001 (held on 2003) and 2005 from Bangladesh Agricultural University, Mymensingh-2202, Bangladesh. He obtained his Ph. D in Food Science and Nutrition from China Agricultural University, Beijing-100083, China in 2016. His major field of research is Food and Nutrition, Food Processing and Product Development. He published more than 50 articles both SCI and Non-SCI in National and International Journal. 